DOI: http://dx.doi.org/10.20435/multi.v21i49.762

\title{
Análise das convergências e divergências nas políticas públicas ecológicas para agricultores familiares a partir da abordagem em desenvolvimento local: um estudo comparativo entre Espanha e Brasil
}

Analysis of differences in public and convergence ecological policy for family farmers approach to local development: a comparative study between Spain and

Brazil

Elizabete Maria da Silva ${ }^{1}$

José Daniel Gómez López ${ }^{2}$

Michel Constantino ${ }^{3}$

${ }^{1}$ Doutoranda pelo Programa de Pós-graduação em Ciências Ambientais e Sustentabilidade Agropecuária, Universidade Católica Dom Bosco (UCDB), Campo Grande, MS (Bolsista CAPES); cotutela Universidade de Alicante, Espanha. E-mail: dasilvabete@yahoo.com.br

${ }^{2}$ Doutor em Geografia; Departamento de Geografia Humana, Universidade de Alicante. E-mail: jd.gomez@ua.es

${ }^{3}$ Doutor em Economia, Universidade Católica Dom Bosco (UCDB). E-mail: michel@ucdb.br 


\section{RESUMO ABSTRACT}

Este artigo examinou a convergência e divergência das políticas públicas direcionadas para produtores agrícolas de base econômica familiar no Brasil e na Espanha. A partir da elaboração de um quadro comparativo, foi possível reconhecer que a Espanha, por ser um país com mais capital social, investimentos estruturais e cultura cooperativista, abarca com maior profundidade as políticas públicas existentes. 0 trabalho é exploratório e utilizou-se de dados bibliográficos, documentais, bem como a percepção da pesquisa de campo realizada anteriormente. Conclui-se que, apesar de melhor apreensão da Espanha no que se refere às políticas públicas existentes, o Brasil adota políticas semelhantes, podendo se esperar avanços análogos. No entanto são necessárias implementações nas políticas

públicas existentes, tanto na Espanha (dependente da PAC), quanto no Brasil, no sentido de garantir a produção agrícola familiar e sua sustentabilidade. Fica evidenciado, no presente artigo, que políticas públicas para agricultura familiar, que garantam o desenvolvimento local, são clamores mundiais.

PALAVRAS-CHAVE organização agrícola familiar capital social sustentabilidade
This article examined the convergence and divergence of public policies for farmers family economic base in Brazil and Spain. From the preparation of a comparative table it was able to recognize that Spain, as a country with more social capital, structural investments and cooperative culture embraces in greater depth the existing policy. The work is exploratory and used to bibliographical, documentary evidence as well as the perception of previously conducted field research. It concluded that although better understanding of Spain in respect of existing policies, Brazil adopt similar policies may be expected advances analogs. However, implementations are required in existing public policies, both in Spain and in Brazil, to ensure the family agricultural production and sustainability. It is shown in this article, that public policies for family farming, to ensure local development, are world clamors.

\section{KEY WORDS}

family farm organization social capital sustainability 


\section{INTRODUÇÃO}

A agricultura familiar, em âmbito mundial, tem enfrentado muitas dificuldades para manter seu grau de produtividade e consequentemente sobreviver. Num processo de adequação ao modelo competitivo vigente, empreendimentos agrícolas familiares buscam novos modelos de negócios, como a produção mais sustentável e ecológica, por meio da organização coletiva, contribuindo assim com o desenvolvimento local.

É consenso, no meio literário, que, nesse contexto, as políticas agrícolas que privilegiem grupos organizados de pequenos produtores agrícolas familiares são importantes (COELHO, 2001). Isso, na medida em que podem criar mecanismos que possibilitem a manutenção e reprodução de modo sustentável, devido a sua grande importância econômica e social. Assim, as politicas públicas constituem importantes instrumentos, mais não únicos, por meio das quais podem ser realizadas as melhores reservas e distribuição de recursos, para suprir a necessidade de manter certo padrão de renda desses produtores, garantir a segurança alimentar e a sua permanência no campo.

Portanto a avaliação final da sustentabilidade de qualquer prática ou sistema agrícola é um ato social e político. Os governos, por meio de incentivos e políticas governamentais, podem possibilitar linhas de custeios e créditos, bem como implantar sistema de parcerias que viabilizem qualquer prática agrícola (IPEA, 2012).

Partindo-se da premissa de que um sistema de produção pode ser sustentável a partir do apoio de programas e políticas públicas, leva-se ao questionamento sobre os modelos agrícolas a serem adotados, visando à subsistência da agricultura de base econômica familiar.

Com a proposta de uma análise dos objetivos políticos para empreendimentos coletivos de produtores agrícolas familiares de base ecológica, o presente trabalho pretende realizar uma pesqui- 
sa analítica comparativa da contribuição das políticas públicas agrícolas para esses empreendimentos, no Brasil e na Espanha, especificamente no Estado de Mato Grosso do Sul e na província de Alicante, respectivamente. Duas regiões com distinto processo de desenvolvimento, mas com uma efetiva participação da mão de obra familiar na produção agrícola.

Fundamentado na metodologia de análise comparativa, foi possível a elaboração de um quadro de convergência e divergências na atuação de empreendimentos cooperativos de produtores agrícolas familiares em relação às políticas públicas ecológicas, a partir da abordagem em desenvolvimento local.

Essa análise pode colaborar na maior efetividade das políticas públicas adotadas para empreendimentos agrícolas familiares de produção ecológica, por meio do intercâmbio intelectual entre os distintos atores. Esse processo poderá viabilizar a obter intersecções sustentáveis, que venham a contribuir na ajuda aos produtores, com aumento dos impactos positivos no meio ambiente e no desenvolvimento local, por meio da melhoria no bem-estar das famílias que vivem da produção agrícola ecológica.

0 presente estudo foi dividido em seis seções, sendo a primeira uma introdução, na qual é destacado o contexto da pesquisa. Na seção seguinte, é descrita a metodologia utilizada e, logo após, é realizada uma revisão bibliográfica dos temas gerais tratados: política pública, desenvolvimento local e a organização agrícola familiar na produção ecológica. Nas duas seções seguintes, é feito um levantamento minucioso das políticas públicas no Brasil e na Espanha. Em seguida, é incluída a seção em que é apresentada a análise das convergências das políticas públicas do Brasil, da Espanha e o desenvolvimento local e, para finalizar, as considerações finais, ou seja, a conclusão da pesquisa. 


\section{METODOLOGIA}

A pesquisa pode ser considerada como de natureza exploratória. A investigação exploratória é realizada em área na qual há pouco conhecimento acumulado e sistematizado. Por sua natureza de sondagem, não comporta hipóteses que, todavia, poderão surgir durante ou ao final da pesquisa, com vista a estudos posteriores (MARQUES et al., 2008).

A pesquisa exploratória é adequada ao trabalho em questão porque, embora haja muitos trabalhos sobre produção ecológica e cooperação, tanto no Brasil como na Espanha, não existe nenhum trabalho relacionando as políticas públicas para esses seguimentos entre os dois países e o desenvolvimento local.

Quanto aos meios utilizados, a pesquisa se baseou em dados e informações bibliográficas e documentais, bem como na percepção da pesquisa de campo realizada. As constatações na pesquisa de campo se referem especificamente à província de Alicante, Espanha, a qual é produto de estágio da pesquisa doutoral sanduíche. Há ainda anotações referentes ao Estado de Mato Grosso do Sul, onde se realiza parte de pesquisa do doutorado.

A partir da metodologia de análise comparativa, o estudo elaborou um quadro de convergência e divergências na atuação de empreendimentos cooperativos de produtores agrícolas familiares, em relação às políticas públicas ecológicas, a partir de indicadores de desenvolvimento local.

0 estudo utiliza dados e informações inéditas e faz comparação pouco explorada na literatura nacional, além de desenvolver processo de análise única com a adaptação de quadro de indicadores de desenvolvimento local elaborado por Oliveira et al. (2013). 


\section{POLÍTICA PÚBLICA, DESENVOLVIMENTO LOCAL E A ORGANIZAÇÃO AGRÍCOLA FAMILIAR NA PRODUÇÃO ECOLÓGICA}

A modernização da agricultura e pecuária acontece em todo o mundo na década de 30, devido a um amplo programa empresarial de caráter transnacional, que teve como justificativa oficial o aumento da produção agropecuária no mundo. Esse programa é introduzido por meio de melhoramento genético de plantas e animais, uso intensivo de insumos industriais, mecanização e redução do custo de manejo. Um processo de transição de desenvolvimento agrícola que ficou conhecido como a revolução verde (BRUM, 1988). Nesse período, iniciam-se as discussões sobre políticas públicas para a agricultura. Inicialmente, essas políticas públicas, foram elaboradas levando-se em conta apenas a agricultura de exportação, que era considerada como de grande importância para as economias dos países (FURTADO, 1983).

Atualmente, ao se referir à sustentabilidade nas políticas públicas para o setor agrário, é usado o termo agroambiental, que é um processo de união de duas vertentes políticas, a política ambiental e a política agrícola. Esse termo começou a ser utilizado em 1985, em um acordo firmado entre a Inglaterra e a Comunidade Europeia (CEE). 0 objetivo, da união dessas vertentes políticas, foi diminuir os impactos ambientais causados pela produção agropecuária (OCDE, 2003).

Políticas públicas, que promovam padrões sustentáveis de produção e consumo são apresentadas, nas diversas conferências mundiais, como um desafio aos governos. Esse aspecto foi enfatizado na Agenda 21, que é documento resultante da Conferência das Nações Unidas sobre o Meio Ambiente e o Desenvolvimento (CNUMAD), ocorrido no Rio de Janeiro em 1992, a Rio-92. Segundo esse documento, o desenvolvimento sustentável só poderá ser alcançado se as nações puderem reduzir ou mesmo eliminar pa- 
drões que sejam insustentáveis para a produção e o consumo, considerados como as principais causas da degradação ambiental no planeta (CNUMAD, 2000). Esse aspecto foi retomado na Rio+20, que aconteceu também no Rio de Janeiro em 2012 (CNUDS, 2012).

Entre alternativas utilizadas por diversos governos, para agricultura familiar, está a utilização das compras públicas sustentáveis (CPS), que é a preferência aos serviços e produtos, considerados como mais favoráveis para a sustentabilidade da sociedade. Há ainda a criação ou a supressão de tributos considerados específicos, bem como oferecimento de subsídios, estabelecimento de uma carteira de produtos que podem ser incluídos como prioritários nas licitações públicas e políticas específicas para aquisição de determinados produtos, como gêneros alimentícios (SAMBUICHI et al., 2014). Portanto são muitas as alternativas para a intervenção institucional no processo de construção da sustentabilidade, principalmente na agricultura familiar.

A produção ecológica é apontada como uma produção mais sustentável, uma possibilidade para a conservação ambiental. As discussões sobre uma agricultura alternativa, em oposição ao modelo adotado no processo agrícola vigente, surgem na década de 70. A proposta desse novo modelo foi justamente contrapor as dificuldades ambientais e sociais que emergem durante o processo de modernização da agricultura (ASSIS; ROMEIRO, 2002).

Esse modelo, de agricultura ecológica, surgiu primeiramente nos países desenvolvidos, como um novo padrão produtivo, que exigiu inovações tecnológicas para minimizar as perdas, preservar o meio ambiente e o bem-estar da população. Isso pelo uso de tecnologias não convencionais que exigiram inovações e mudança de comportamento, não apenas por valores morais e étnicos, mas também para atender clientes e consumidores com opção de consumo, cada vez mais preocupados com sua saúde, com sua qualidade de vida e de seus descendentes (CAPORAL; COSTABEBER, 2002). 
Os consumidores de produtos ecológicos possuem particularidades diferenciais, em face aos clientes que consomem produtos convencionais. Na comercialização dos produtos agroecológicos, há um importante fator a ser considerado, que é o conceito de fair trade. Esse conceito se justifica nas práticas injustas do mercado global, no que se refere à distribuição de renda, as quais afetam principalmente os países subdesenvolvidos. A origem de tal conceito se baseia no "consumo ético", conceito que teve início na Europa com a emergência de Organizações de Comércio Alternativo (ATOs), como Ten Thousand Villages em 1946, Fair Trade Organisatie em 1967 e Global Exchange no ano de 1988 (LEVI; LINTON, 2003).

Nesses comércios, o consumidor se dispõe a pagar não o estipulado pela costumeira oferta de mercado, conforme a demanda, ou pelo preço de mercado, mas, sim, um preço que seja considerado justo, tanto para o produtor quanto para o consumidor, por meio da intermediação direta entre estes. Há ainda os padrões sociais e ambientais equilibrados nas cadeias produtivas, promovido por meio de encontros de produtores responsáveis com consumidores éticos (LEVI; LINTON, 2003). A premissa é que o consumidor tem a segurança de que o preço pago está sendo distribuído de forma equitativa dentro da cadeia produtiva.

No entanto a produção ecológica hoje é considerada um nicho de mercado, muitas vezes explorado por grandes empresas agroalimentares transnacionais, gerando dificuldade de inserção no mercado do produtor agrícola familiar. Há, ainda, as dificuldades no consumo, em que o consumidor de baixa renda é excluído, pois atualmente é uma produção destinada a quem tem possibilidade financeira de consumo. Os movimentos ecológicos, formados por organizações de produtores familiares e intelectuais, defendem que, nesse caso, uma forma de reduzir o preço são os arranjos coletivos de produtores ecológicos, que eliminam esses 
nichos de mercado, por meio da cooperação (SEVERINO, 2000; CAPORAL; COSTABEBER, 2002).

A cooperação proporciona situações em que várias pessoas se beneficiam da organização para resolver os problemas comuns de produção ou comercialização, o que, muitas vezes, individualmente seria impossível (PAULI, 2006). Esse fator é o que caracteriza a ação coletiva, que, para Almeida e Ferrante (2009), é determinada pela confiança gerada dentro de uma rede, que produz um ambiente de interdependência, possibilitando as ações em prol do coletivo. Para Lopes e Baldi (2005), essas relações criam laços sociais, fortes e fracos, que geram possibilidades de sustentabilidade desses empreendimentos, por meio da competitividade cooperativa, possibilitando que eles tenham vantagem competitiva, um novo mercado específico, que pode promover maiores ganhos econômico, maior bem-estar para os envolvidos e, consequentemente, estímulo ao desenvolvimento local.

O progresso é o anseio de toda nação. Seus cidadãos desejam usufruir de todo o conforto e bem-estar possível, porém o progresso sem sustentabilidade tem desgastado o meio ambiente, muitas vezes de forma irrecuperável. 0 desenvolvimento sustentável, quando acontece em um local definido, onde os agentes se apropriam do processo através das próprias potencialidades existentes no local, por meio de uma conexão solidária entre si e com o entorno, caracteriza o desenvolvimento local (JARA, 1998; ÁVILA, 2006).

A participação efetiva da comunidade, por meio da valoração humana, individual e do lugar, é essencial para obter desenvolvimento. O autor Martín (1999) específica que a satisfação das necessidades humanas fundamentais, por meio da participação efetiva dos envolvidos, é primordial para que ocorra o desenvolvimento local. Entretanto, ainda segundo o autor, é necessário que sejam criadas condições para que haja o protagonismo pessoal e comunitário, por meio das políticas públicas. 


\section{POLÍTICA PÚBLICA PARA PRODUÇÃO ECOLÓGICA DE AGRICULTORES FAMILIARES NO BRASIL}

As políticas públicas para a agricultura, no Brasil, começaram a tomar foco na década de 50 . No entanto seriam implementadas apenas a partir da década de 60 , mais especificamente em 1965 (COELHO, 2001).

Até a década de 30, a agricultura brasileira, principalmente aquela voltada para a exportação, influenciava fortemente a economia e, por esse motivo, possuía algum apoio oficial. Quanto à produção agrícola para o mercado interno, esta não tinha nenhum apoio estatal e era beneficiada apenas quando havia crise no setor externo (FURTADO, 1983). Historicamente o Brasil tem passado por diferentes planos agrícolas, sendo estes influenciados pelos planos econômicos vigentes, que impactaram na política de crédito e no estímulo à produção.

Ainda assim, a importância da agricultura familiar no Brasil foi enfatizada nos sete censos agropecuários realizados no Brasil desde 1950, nos quais a participação dos agricultores que têm menos de 100 hectares nunca se distanciou de $90 \%$ do total de estabelecimentos, com $20 \%$ da área. Esses dados indicam a permanência desses produtores de pequeno porte por toda a segunda metade do século. Essa permanência no cenário agrícola, apesar dos constantes desafios, mostra que esse segmento está em constante mudança, compondo estratégias de sobrevivência e reprodução, as quais dependem do meio no qual os agricultores familiares estão inseridos (VEIGA et al., 2001).

Os dados apresentados por Veiga et al. (2001), são corroborados por De Souza Barbosa (2012), ao escrever que, no Brasil, 84\% dos empreendimentos agropecuários são de agricultores familiares, os quais ocupam um território $24,3 \%$ do total agrícola, e são responsáveis por cerca de $70 \%$ da produção alimentar no país. Esse resultado pode estar ligado à falta de interesse dos gran- 
des empresários agrícolas em produzir para abastecer o mercado interno, devido aos altos custos para produção de alimentos de subsistência e seu baixo preço no mercado. Há ainda a dificuldade do produtor agrícola familiar em enfrentar a concorrência com essas empresas transnacionais por uma fatia do mercado externo, tendo que sujeitar a sua produção ao âmbito local.

É notória a rotatividade do pequeno agricultor familiar no Brasil, o que dificulta a territorialização e a contribuição para com o desenvolvimento local. Os assentamentos, uma forma de concessão de terras por meio da reforma agrária, surgiu como medida política, uma tentativa de resolver os problemas sociais no campo sem grande preocupação com as questões sociais de pobreza, exclusão, ou incremento da produção agrícola da agricultura familiar (BERGAMASCO, 1997). Ainda assim, contribuíram para o retorno ao campo, de muitos pequenos agricultores que viviam nas periferias das cidades. No entanto a falta de políticas que garantam fatores de bases essenciais para o desenvolvimento tem levado esses agricultores a um constante vai e vem pelo território do país (SILVA; CEREDA, 2014).

A partir dessas constatações, o Brasil busca elaborar políticas agrárias que favoreçam a manutenção dos pequenos produtores no campo, ou permitam o retorno à agricultura de indivíduos em situação precária, instalados na periferia das grandes cidades. Entre as alternativas de políticas apresentadas pela literatura, a disponibilidade de crédito ocupa um lugar de destaque. 0 crédito pode facilitar o acesso do pequeno produtor às novas tecnologias e, consequentemente, a inserção no mercado (BUAINAIN; GARCIA, 2013). No entanto as políticas de crédito existentes no país, não atendem a demanda desse setor, devido a distancia entre as instituições e o público-alvo, bem como a falta de assistência técnica na elaboração dos projetos (SUCUPIRA; FREITAS, 2011; ABRAMOVAI, 2001).

A política pública específica para agricultura familiar só apareceu em 1996, com o Programa de Fortalecimento da Agricultura 
Familiar (PRONAF) e, em 2006, quando emergiu a lei que fixou diretrizes para esse segmento. As novas reflexões, incorporando a pluriatividade e as de cunho político, levaram o governo federal a readequar as políticas para o setor agrícola, propondo-se, inclusive a revisão do Manual do Crédito Rural (SAMBUICHI et al., 2014).

Outra política vigente de apoio à agricultura familiar, no Brasil, são as compras públicas, medidas pelas quais o governo incentiva, por meio do consumo, a geração de produtos mais sustentáveis. No Brasil, as compras públicas se dão por meio do Programa de Aquisição de Alimentos (PAA) e o Programa Nacional de Alimentação Escolar (PNAE). O PAA é uma política que já vinha sendo desenvolvida no Brasil, mas que foi regulamentada somente em julho de 2003, no artigo 19 da Lei no 10.696. Por meio dessa política, o governo compra produtos de agricultores familiares para garantir a segurança alimentar da população de baixa renda (BIANCHINI; MEDAETS, 2013).

O PNAE surgiu em 1955, com o Decreto n. 37.106, que é quando foi criada a Campanha da Merenda Escolar. Portanto o objetivo inicial era garantir a segurança alimentar das crianças matriculadas nas escolas públicas. A novidade desse programa foi o sancionamento da Lei no 11.947/2009, que estabeleceu novas regras para o PNAE ao determinar, por meio do Artigo 14, que $30 \%$ das compras para esse fim, sejam feitas de produtores da agricultura familiar (SAMBUICHI et al., 2014).

Sambuichi et al. (2014) citam, como as principais contribuições das compras públicas, a diversificação produtiva, o apoio à agricultura orgânica e agroecológica, bem como o estímulo ao consumo de produtos locais. As maiores barreiras ainda são relacionadas à estrutura de logística e transporte, devido à distancia dos produtores dos centros de consumo. Há ainda a dificuldade de beneficiamento e armazenamento, bem como a necessária melhoria da assistência técnica e da oferta de crédito para responder especificamente às necessidades desse setor. Essas 
compras também são usadas pelo governo brasileiro com o fim de incentivar uma produção mais sustentável. E os valores pagos aos produtores, tanto pelo PAA, quanto pelo PNAE são $30 \%$ a mais que o convencional para produtos comprovadamente produzidos de forma ecológica.

Segundo Bianchini e Medaets (2013), no Brasil o aparato legal que versa sobre o tema relacionado à produção ecológica, ou como designado no país, agroecológicos, estrutura-se a partir do código florestal (Decreto 23.793) e do Código de Águas (Decreto 24.643), criados em 1934. Esse aparato legal vem sofrendo modificações, através de constantes debates no meio acadêmico, com marcada preocupação de diversas organizações sociais do campo e da floresta, e da sociedade em geral, relacionada à necessidade da produção de alimentos saudáveis com a conservação dos recursos naturais.

O movimento em prol de uma produção mais sustentável levou à estruturação participativa, no Brasil, e à criação, em 2012, da política Nacional de Agroecologia e Produção Orgânica (PNAPO), instituída em 2012, quando também é aprovado o Plano Nacional de Agroecologia e Produção Orgânica (PLANAPO). Estes são regulamentados pelo Decreto n. 7.794/2012, que também estabelece como meio de gestão da Política do PLANAPO a Comissão Nacional de Agroecologia e Produção Orgânica (CNAPO) e a Câmara Interministerial de Agroecologia e Produção Orgânica (CIAPO) (BIANCHINI; MEDAETS, 2013).

Apesar dessas iniciativas, as dificuldades para os agricultores familiares, principalmente assentados, têm-se agravado nos últimos anos, a "encruzilhada" na qual se encontra a agricultura familiar no Brasil. 0 fato ocorre, principalmente, pela falta de perspectiva para os que dela vivem, causada pelos altos custos para produzir, incluindo tempo, força física e a desvalorização do produto agrícola, apesar de todo o incentivo para a permanência do agricultor no campo. Há ainda o aumento da produção 
da agricultura familiar, causado pela modernização dos grandes estabelecimentos agrícolas que gerou ganhos na produtividade rural, e uma queda real nos preços dos produtos produzidos, consequentemente encurralando os pequenos estabelecimentos com dificuldade de inovação tecnológica (NAVARROS; CAMPOS, 2013).

Buscando alternativas para o pequeno produtor rural, no Brasil, segundo Borges (2012), tem sido dada ênfase a princípios associativos ou coletivos de produção agrária, sendo este o único meio pelo qual os produtores podem acessar determinados mecanismos governamentais de ajuda aos produtores, tais como o PNAE e PAA.

No entanto fomentar a cooperação agrícola, no Brasil, é um desafio, tanto para os movimentos organizadores de agricultores familiares, quanto para os próprios agricultores, em decorrência de sua percepção individual e familiar em trabalhar no campo. Vários questionamentos são apontados por Schimitz et al. (2007), os quais procuram entender por que determinadas atividades são desempenhadas de maneira coletiva, enquanto outras são desempenhadas individualmente por agricultores familiares. 0 fato é que, no Brasil, são muitas as dificuldades enfrentadas por pequenos produtores familiares, tais como a insegurança para fazer investimentos, planejar as atividades e ampliar sua capacidade produtiva, que podem ser superadas em um contexto no qual haja interação entre os produtores, por meio da cooperação (SOUZA FILHO; BONFIM, 2012).

\section{POLÍTICAS AGRÍCOLAS NA ESPANHA}

A agricultura na Espanha, como em todos os países da União Europeia, é contemplada pela Política Agrícola Comum (PAC). A PAC já está presente nas discussões políticas na União Europeia (UE) na década de 50, pois, no tratado de Roma, em 1957, essa iniciativa é considerada nos artigos 39 e 47. No entanto ela só é 
criada a partir de 1962, na Conferência de Stressa. Os objetivos principais da PAC eram de garantir a segurança alimentar dos países membros da União Europeia a preços razoáveis para os consumidores, determinar uma renda mínima para os agricultores familiares e aumentar a produção da agricultura (EUR-LEX, s.d.). 0 processo de implantação da PAC é justificado pela escassez alimentar vivenciada após a Segunda Guerra Mundial e de outras questões de índole geopolítica.

O Mercado Comum Europeu (CEE) baseou-se em quatro princípios fundamentais para atingir os objetivos propostos com a PAC, sendo estes a unidade de mercado; a preferência comunitária, ou seja, a proteção da produção interna por meio de criação de tarifas ou não; a solidariedade financeira, por meio da criação de um Fundo Europeu de Orientação e Garantia Agrícola (FEOGA [FEOGA-Orientação e FEOGA-Garantia]), com que cada país seria beneficiado segundo a sua participação (EUR-LEX, s.d.).

A PAC inicialmente foi considerada um sucesso, pois, junto com um período áureo de crescimento econômico europeu, garantiu uma produtividade média agrícola superior à dos Estados Unidos. 0 abastecimento interno foi garantido, gerando um excedente para exportações, e a renda média do trabalhador agrícola superava a renda média de trabalhadores de outros segmentos econômicos (LAGARDE, 2004).

Porém, durante o período áureo da PAC, a política de sustentação de preços teve que ser garantida, o que causou, principalmente, o comprometimento das finanças comunitárias. Houve ainda um processo de dificuldades mercantis da UE com outros países, tais como Estados Unidos e os países exportadores de produtos agropecuários denominados grupo dos Cairns, devido à política de proteção adotada. Entre os efeitos negativos, ainda figuram a erosão e contaminação do solo e das águas (NASCIMENTO, 2005).

A PAC foi criada levando-se em conta a necessidade de seus países fundadores, a Alemanha, Bélgica, França, Itália, Luxemburgo 
e Países Baixos. Apesar do ingresso dos novos países, ainda continuou a serem levadas em conta, principalmente, as necessidades dos países fundadores, sendo que pelo menos $70 \%$ dos recursos eram para atender as subvenções e proteger a produção desses países. No entanto são inegáveis os benefícios da PAC no desenvolvimento europeu, pois é a única política realmente comum na Europa (MOYANO-ESTRADA, 2013).

Assim, em 1992, aconteceu a primeira grande reforma da PAC, que ficou conhecida como reforma de McSharry. Segundo Azcárate (2007), a partir da reforma McSharry, começou a reflexão sobre a diminuição dos gastos institucionais por meio dos pagamentos diretos como complemento a renda dos agricultores. Esse processo é consolidado na reforma de 2000, na qual também se começou a discussão sobre apoio a um desenvolvimento agrícola mais sustentável (EUR-LEX, s.d.).

Muitas são as críticas sofridas pela PAC. Para MoyanoEstrada (2013), essa crítica advêm de segmentos que representam a agricultura familiar e de pressões internacionais, de países que se sentem prejudicados com a política de proteção da UE. Há também o descontentamento de países membros da UE, que já não se sentem contemplados com a PAC, tais como Alemanha e Reino Unido, que não possuem uma economia fundamentada na agricultura. Há ainda outros países, como a França e Reino Unido, que, apesar de um percentual da população significativamente agrícola, apresenta resistência em manter uma PAC nos níveis desenvolvidos nos últimos anos. No entanto essas são questões muito complexas para serem discutidas no presente trabalho.

0 certo é que a PAC tem uma repercussão positiva para autores latinos americanos, entre estes brasileiros como Nascimento (2005), que veem, no processo histórico de criação e desenvolvimento da PAC, uma preocupação social com a agricultura familiar, o que, segundo o autor, pode ser notado pela manutenção dos estabelecimentos agrícolas, mesmo que estes sejam muitas 
vezes considerados não competitivos e ineficientes, segundo os critérios do mercado. Ainda segundo o autor, como no Brasil, as grandes propriedades sempre foram mais beneficiadas, no entanto o pequeno produtor agrícola foi mais protegido, pela sua importância social.

Para os autores europeus, entre estes, Gómez López (2008/2009), esta afirmação não tem sustento científico. Segundo o autor, as distribuições das ajudas diretas aos produtores, desde o início da PAC, ampliaram as desigualdades econômicas na produção agrícola espanhola, visto que quem recebia os maiores montantes eram justamente os produtores mais ricos. Ainda segundo o autor, a partir da reforma de 1992, esse aspecto se fortaleceu, visto que as ajudas, antes destinadas exclusivamente a agricultores familiares, passou a ser ampliada a qualquer tipo de exploração agrícola, desde que comprovada a viabilidade do empreendimento.

A reforma da PAC para 2014 a 2020 aconteceu no final de 2013, com um orçamento de 370 bilhões de euros para o período 2014-2020,12\% menor que o orçamento dos últimos sete anos, que foi de 412,6 bilhões de euros, e com o ingresso de mais três países (Bulgária, Romênia e Croácia), sendo agora 28 os países membros. Essa nova reforma da PAC possui uma orientação territorial, que objetiva a coesão da UE, por meio de desenvolvimento de regiões consideradas mais atrasadas, reduzindo as desigualdades gerais. Foram mantidos os dois pilares nos quais a PAC se sustenta desde 2005, como primeiro pilar, os pagamentos diretos para os agricultores em atividades, e o segundo, a política de desenvolvimento rural (EUROPEAN COMMISSION, 2013).

Segundo Moyano-Estrada e Ortega (2014), a nova mudança de prioridades na PAC a difere totalmente das reformas anteriores, pois de uma PAC antes destinada especificamente ao desenvolvimento do setor agrário, volta-se nesse momento ao desenvolvimento setorial. Há, ainda, nessa nova modalidade da 
PAC, o incentivo a investimentos voltados a ações que contribuam para o melhoramento do bem-estar da sociedade, com a utilização dos recursos naturais de forma mais racional, para produção de alimentos, visando a sua preservação. Portanto é estabelecido, nessa reforma, um maior incentivo à multifuncionalidade da agricultura, cuja função não é apenas a produção de alimentos, mas também a preservação de bens públicos.

Muitos são os questionamentos sobre a aplicabilidade das ajudas aos empreendimentos agrícolas familiares multifuncionais, sobre o controle e incentivos dos recursos destinados a esse fim. O conceito de multifuncionalidade da agricultura já é assumido em La Declaraión Cork (1996) e na La Agenda 2000 (1997), documento que vai estabelecer as bases tanto econômicas quanto financeiras da UE nos períodos de 2000-2006. Segundo esse conceito, o meio rural tem dupla função, produzir alimentos e garantir serviços públicos essenciais como o bem-estar dos cidadãos e do meio ambiente.

Para alguns autores como Nascimento (2005) e Souza e Diegues (2012), nos últimos anos, houve uma drástica diminuição dos estabelecimentos agrícolas da UE, como em todo o mundo; no entanto, muito mais que em outros países, esses estabelecimentos foram preservados, mantendo-se o vínculo de muitos agricultores com a atividade agrícola, fato que, segundo os autores, pode ser atribuído a PAC.

Segundo Gómez López (2004), a grande contribuição no processo de resistência dos agricultores espanhóis está relacionada ao processo de organização cooperativista, pois, segundo o autor, as cooperativas não resolvem a problemática vivenciada pela agricultura em todo o mundo, no entanto prolonga seu processo de sobrevivência.

A organização cooperativa no continente europeu, diferente do que ocorre no Brasil, possui um cenário muito favorável, pois essas organizações fazem parte da cultura agrícola dos pequenos 
produtores rurais. Na Espanha, esse processo se inicia um pouco mais tarde, no entanto, conforme Medina-Albaladejo (2013), em 1887, quando foi criada a lei de associações, na Espanha já havia diversas instituições cooperativas.

A Espanha está classificada, em superfície, como o primeiro país de produção ecológica da UE (ESPAÑA, 2013a). A produção ecológica foi regularizada, na Espanha, em 1989, pelo regulamento (CEE) 2092/91, que se refere a essa produção, de forma genérica, como “Agricultura Ecológica”. A partir de 2009, essa produção é regida pelo regulamento (CE) 834/2007 do Conselho de 28 de junho de 2007, em que são definidas as normas de rotulagem e de produtos ecológicos provenientes de outros países (ESPAÑA, 2015).

Quanto ao controle e certificação da produção ecológica, este é realizado pelos conselhos ou comitês de agricultura territorial, organismos públicos de competência de cada comunidade autônoma. Algumas comunidades autônomas, tais como Andalucía e Castilla-La Mancha, designaram organismos privados para realizar esse controle e certificação (ESPAÑA, 2015).

Segundo estudo realizado pelo Ministerio de Agricultura Alimentación y Medio Ambiente (MARM) a demanda de alimentos produzidos ecologicamente foi promovido por grupos organizados de consumo ecológicos, sendo que esses grupos surgiram na Espanha nos anos oitenta e se ampliaram nos anos noventa. Esses estudos ainda informam que pelo menos $5 \%$ do consumo de produtos ecológicos se dão por meio desses canais curtos (HISPA COOPE, 2011).

Ainda de acordo com estudos do MARM, cerca de 72,5\% da população espanhola já escutaram falar de alimentos ecológicos, mas destes, 62,1\% nunca consumiram esses alimentos, um número altíssimo para uma população de um país considerada criteriosa na escolha de produtos para sua alimentação. Os motivos apontados pelo citado órgão é o desconhecimento da população 
sobre o significado de alimentos ecológicos, a dificuldade de encontrar tais produtos no mercado e principalmente a diferença de preço (HISPA COOPE, 2011).

Assim, diante da importância de empreendimentos de agricultores familiares que se organizam coletivamente para produzir ecologicamente, é construída a análise apresentada a seguir.

\section{CONVERGÊNCIAS E DIVERGÊNCIAS NO PROCESSO DE APREENSÃO DAS POLÍTICAS PÚBLICAS ENTRE BRASIL E ESPANHA E A EFETIVIDADE DESTAS PARA 0 DESENVOLVIMENTO LOCAL}

A preocupação com a produção agrícola familiar, sua sustentabilidade e do ambiente natural, bem como com a saúde das gerações atuais e de seus descendentes, é mundial. No entanto as formas escolhidas para incentivos a esse setor é diferenciada.

As políticas públicas adotadas por um país considerado emergente, o Brasil, e para um país de primeiro mundo, Espanha, podem ser consideradas como intervencionistas, com objetivo de direcionar a produção agrícola conforme demanda social. No entanto, entre esses dois países, quais são as políticas públicas mais efetivas? 0 que determina sua efetividade? Tentando responder a essas questões, com base no arcabouço teórico abordado nas seções anteriores do texto, entre políticas públicas no Brasil e Espanha e sua contribuição para o desenvolvimento local, foram sistematizadas as convergências e divergências levando em conta as realidades da província de Alicante, Espanha e o Estado de Mato Grosso do Sul, Brasil (Quadro 1). 


\begin{tabular}{|c|c|c|c|c|c|c|c|}
\hline & 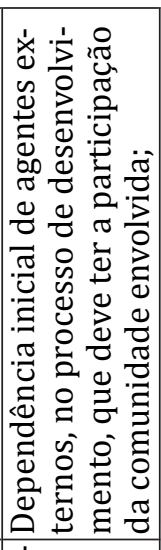 & 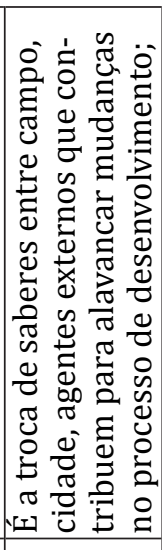 & 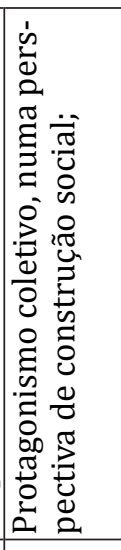 & 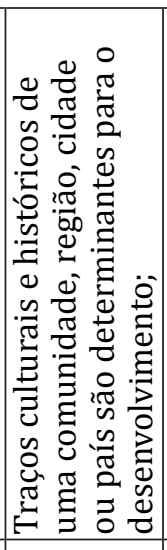 & 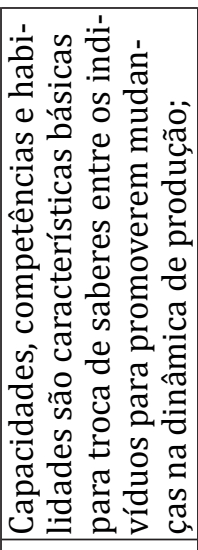 & 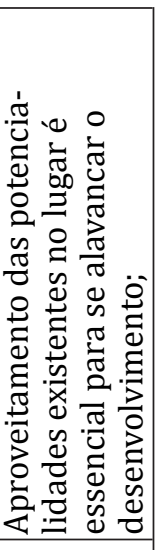 & 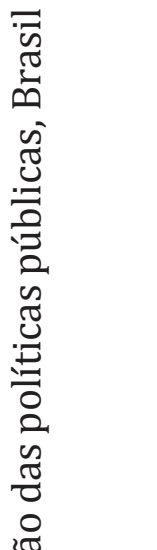 \\
\hline 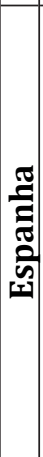 & 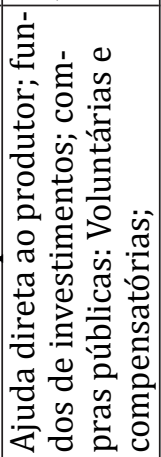 & 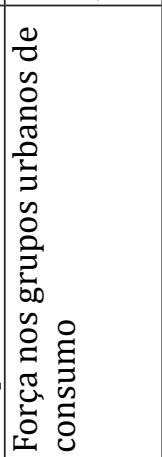 & 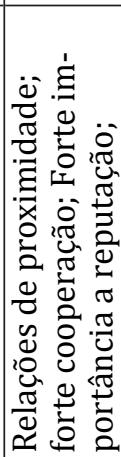 & 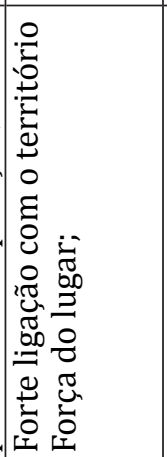 & 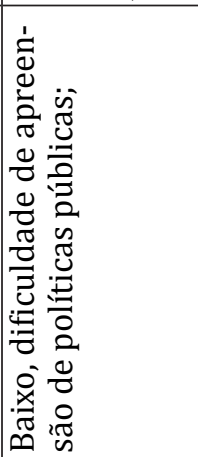 & 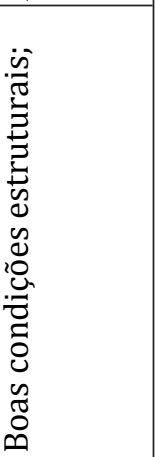 & 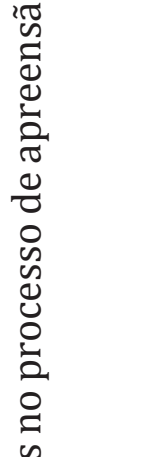 \\
\hline $\begin{array}{l}\overline{5} \\
\overline{5} \\
0 \\
0\end{array}$ & 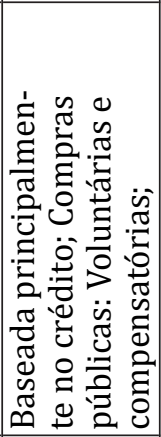 & 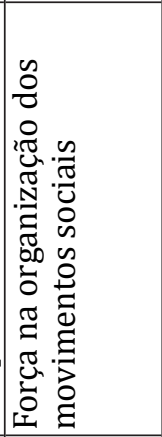 & 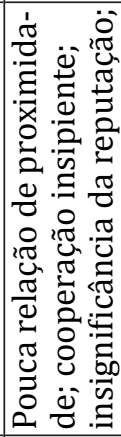 & 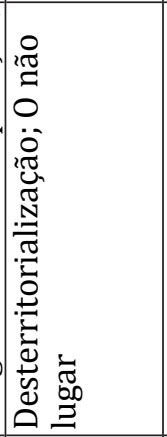 & 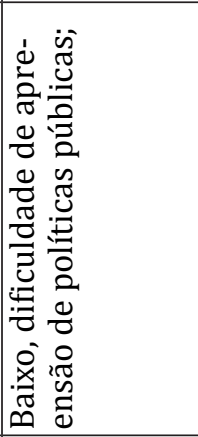 & 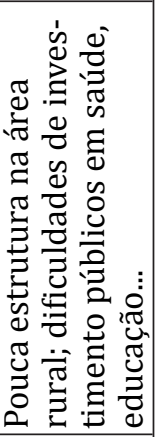 & 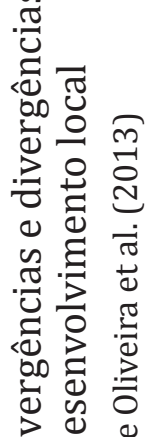 \\
\hline 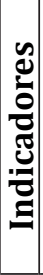 & 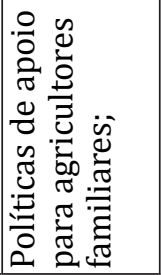 & 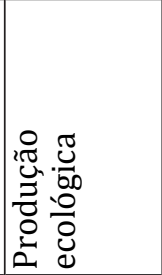 & 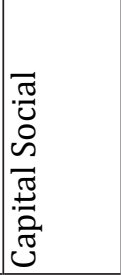 & 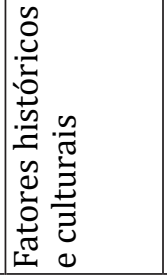 & 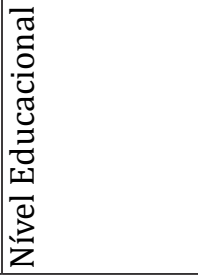 & 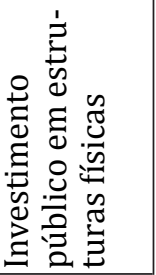 & 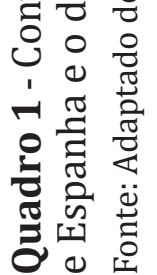 \\
\hline
\end{tabular}


Segundo Sumpsi et al. (1997), os países desenvolvidos possuem uma característica geral, que é o protecionismo e o intervencionismo agrário por meio das políticas públicas adotadas, pois a soberania alimentar é um setor estratégico para qualquer nação. Segundo o autor, essas políticas são tipificadas em incentivos econômicos sobre ações voluntarias (incentives schemes) e ajudas condicionadas (cross-compliance).

Pode se salientar que o intervencionismo e protecionismo agrário não é uma virtude apenas de países desenvolvidos, pois as políticas agrárias no Brasil possuem o mesmo cunho das políticas espanholas. Conforme exposto, as principais políticas apresentadas são as políticas de crédito, que tem o objetivo de beneficiar e proteger a agricultura familiar. Mesmo que no Brasil, como na Espanha, haja desvios de finalidades, e as grandes produções empresariais muitas vezes sejam mais beneficiadas.

No entanto, conforme análise da presente pesquisa, as políticas adotadas de incentivo à agricultura familiar e ecológica, tanto no Brasil, como na UE, podem ser classificada como voluntárias e, em determinados casos, condicionadas. Como exemplo podem ser citados o PAA e PNAE, em que o agricultor tem um incentivo de $30 \%$ na comercialização da produção ecológica e tem a possibilidade de comercializar sua produção, seja ecológica ou não; no entanto o acréscimo dos $30 \%$ está condicionado à certificação ecológica. Em relação à organização coletiva, o incentivo do governo para tal processo é realizado mediante a utilização dos mecanismos de comercialização disponíveis à agricultura familiar. Os agricultores só podem acessar determinado benefício se estiverem organizados em associações ou cooperativas.

0 mesmo fato pode ser observado na Espanha, em relação aos mecanismos de compras do governo, de produtos da agricultura familiar, por meio da fundação banco de alimentos. Esses alimentos, frutas e hortaliças são doados para famílias em condição de insegurança alimentar. No entanto o produtor 
individual não tem acesso a tal programa, este está disponível apenas a empreendimentos cooperativos que estejam associados a "Organizaciones de productores de frutas y hortalizas" - OPFH (ESPAÑA, 2013b). Portanto também pode ser classificado como um benefício condicional.

Em relação aos mecanismos de comercialização institucional, no que se refere ao Brasil, há uma dependência dos agricultores para com esses meios de comercialização. Muitos produtores brasileiros só possuem estes como forma de comercializar a sua produção. Quanto à Espanha, o que é vendido por meio dos mecanismos de comercialização institucionais é insignificante, quando comparado ao valor total comercializado pelos produtores agrícolas familiares, o que demonstra a evolução desses agricultores, bem como a sua independência em relação a esse mercado.

Na Espanha, segundo Gliessman et al. (2007) e Ortiz-Pérez (2015), o movimento dos grupos de consumidores ecológicos foi decisivo para fomentar a produção ecológica, sendo um movimento que nasce nos centros urbanos, a partir da demanda apresentada pelos consumidores.

No Brasil, a discussão sobre a produção ecológica nasce no meio acadêmico. Segundo Oliveira et al. (2013), é o meio acadêmico, em conjunto com a organização dos produtores agrícolas familiares, que, gradativamente, formaram redes e instituições que estão à frente do debate por uma produção mais sustentável. Essa produção é denominada agroecológica e evoluiu de uma prática produtiva para um movimento social de expressão nacional.

No estudo sobre as experiências agroecológicas no Brasil, Oliveira et al. (2013) concluíram que a agroecologia é uma estratégia para o desenvolvimento local, sendo que a maioria dos produtores são familiares estão envolvidos em alguma forma de associativismo e contam com apoio de organizações externas que atuam como agentes de desenvolvimento. 
Segundo Sumpsi et al. (1997), as políticas de enforcement são mais eficazes que as políticas de caráter voluntário. No entanto a presente pesquisa, com enfoque no Desenvolvimento local, analisa que outros fatores são mais determinantes, entre estes o capital social, os fatores históricos e culturais, o nível educacional e o capital estrutural existente.

Foi observado, na análise realizada no decurso desta pesquisa em cooperativas da província de Alicante, que um fator que contribui para a organização coletiva na Espanha é o capital social. As pessoas nascem e morrem na mesma região, portanto possuem relações com familiares e vizinhos no local. A reputação é outro fator condicionante do comportamento das pessoas no lugar, o que evita comportamentos oportunistas, o que foi diagnosticado por Bonfim e Batalha (2012). Quanto ao fator histórico cultural, o cooperativismo é inerente ao processo histórico da Espanha, mesmo tendo começado mais tarde em relação aos outros países do continente europeu (MEDINA-ALBALADEJO, 2007).

O Brasil possui distintos processos organizativos da agricultura familiar. E a região sul do País apresenta maiores avanços, o que já foi diagnosticado como herança cultural de descendentes de europeus que majoritariamente colonizaram a região (BRASIL, 2006).

A região Centro Oeste do País, é uma região com um processo de colonização distinto da região sul do país, especificamente o estado do Mato Grosso do Sul, que é caracterizado por uma população de migrantes de diversas regiões do Brasil. Há muitas divergências culturais e ideológicas, em que predominam rivalidades culturais, com projeções de determinadas culturas nacionais. Portanto, especialmente entre os agricultores familiares assentados, a organização coletiva é incipiente, apesar de todo o incentivo para tal organização entre os produtores. No citado contexto, mesmo as políticas de enforcement possuem dificuldades de serem implementadas, diferente do atestado 
por Sumpsi et al. (1997) de que estas são mais eficazes que as de cunho voluntárias.

O lugar é o espaço das relações humanas, isto é, das práticas e convivências cotidianas que adquirem significado e sentido a partir da realidade material e ligação emocional aos objetos, e está simultaneamente ligada aos laços territoriais, econômicos e culturais. Portanto o lugar é o palco dos acontecimentos que perpassam a vida dos indivíduos. A pessoa recém-chegada ao lugar leva tempo para assumi-lo como seu novo espaço de vida, confrontar a noção de espaço com o novo vivido, criar novos laços de amizade e solidariedade, ou seja, territorializar-se (PIRES, 2007). Assim, é indiscutível a ligação de territorialidade e desenvolvimento local. Ao se falar de local, "está se referindo à escala das inter-relações pessoais da vida cotidiana, que sobre uma base territorial constroem sua identidade" (MARTINS, 2002, p. 54).

Outro fator que pode ser primordial para a implementação de políticas públicas que favoreçam o desenvolvimento local, é o nível educacional de um determinado grupo, pois isso pode permitir a compreensão e internalização destas, bem como os fatores condicionantes para acessá-las. Silva e Khan (1996), ao analisarem a importância do nível educacional do agricultor na geração da renda rural, concluíram que esse fator tem influência positiva no valor da produção, proporcionando aumento expressivo na eficiência técnica e econômica.

O nível de escolaridade dos trabalhadores agrícolas familiares na região centro oeste já foi diagnosticado como baixo, sendo muitos analfabetos ou apenas alfabetizados, principalmente devido à faixa etária e às diversas migrações sofridas por esses agricultores. A possibilidade de dar continuidade aos estudos é dificultada pelas grandes distâncias existentes entre os centros escolares e a moradia desses agricultores (SILVA; CEREDA, 2014).

Em uma análise das disparidades educativas da Espanha rural contemporânea, por Gutierrez (2004), foi identificado que 
os produtores agrícolas familiares na Espanha, possuem nível educacional baixo, porém todos são alfabetizados, sendo a maioria com o primário completo. Grande parte desses agricultores é idosa, remanescentes de uma época em que o ensino não era muito valorizado pelo trabalhador agrícola.

No entanto a maioria dos produtores agrícolas familiares na Espanha está organizada em cooperativas, as quais fornecem assessorias e assistência técnica, o que não acontece em várias regiões no Brasil, devido à percepção individual e familiar de se trabalhar no campo (SCHIMITZ et al., 2007).

Quanto à questão de investimentos públicos em estruturas físicas, Reis (2008), em um trabalho sobre gastos públicos, descreve a importância dos investimentos públicos em bens públicos estruturais, para o desenvolvimento. Na Espanha, conforme observado na província de Alicante, o nível de investimento em bens públicos é histórico. As vias agrícolas são pavimentadas, e as propriedades agrícolas familiares, próximas aos centros urbanos. Há acesso ao transporte público pelos moradores e possibilidade educacional para os filhos deles.

No Brasil, no que se refere ao Estado de Mato Grosso do Sul, esse é um estado "jovem", fundado em 1977, portanto com muitas deficiências estruturais. Esse Estado possui uma baixa densidade populacional, com grandes distâncias entre os locais de produção e os mercados, fatores esses que reforçam a dificuldade de sobrevivência dos pequenos produtores, entre eles os assentados (GIRARDI, 2008).

Assim, ao realizar uma análise da convergência e divergência das políticas públicas para agricultores familiares e o Desenvolvimento Local, no Brasil e Espanha, conclui-se que ambos os países possuem similaridades na adoção de políticas públicas, no entanto, no que se refere ao acesso a essas políticas e à implementação do desenvolvimento local, o Brasil possui ainda muitas dificuldades, o que é natural, em vista dos distintos processos de desenvolvimento entre os dois países. 


\section{CONSIDERAÇÕES FINAIS}

Pelo exposto é possível observar que as proposituras para a agricultura familiar brasileira, tais como a cooperação entre agricultores, produção ecológica, entre outras, estão direcionadas à evolução de um desenvolvimento mais sustentável, de base local, como observado em países em um processo mais avançado de desenvolvimento, como a Espanha. Portanto há convergências entre as políticas públicas para a agricultura familiar no Brasil e na Espanha, e as divergências estão na capacidade de apreensão dessas políticas, devido a fatores estruturais culturais e educacionais. No entanto é possível afirmar que o Brasil possui possibilidades para alavancar o mesmo nível de desenvolvimento, isso por meio de investimentos que possam sanar as falhas diagnosticadas.

Os arranjos produtivos locais são importantes para um desenvolvimento mais sustentável da agricultura familiar. Esses arranjos produtivos, no caso as cooperativas agrárias, são fatores primordiais para o incentivo a uma produção ecológica, que garanta o desenvolvimento local. Esse fator efetivamente só será conquistado com incentivos aos produtores locais, tanto no Brasil como na Espanha, país cuja ajuda efetiva a esse segmento tem diminuído gradativamente nos últimos anos. Portanto, as políticas públicas que garantam a sustentabilidade desses empreendimentos e, consequentemente, a soberania alimentar das nações são clamores mundiais.

\section{REFERÊNCIAS}

ABRAMOVAY, R. Finanças de proximidade e desenvolvimento territorial no semiárido brasileiro. Brasília: Ministério do Desenvolvimento Agrário, Fundo Internacional de Desenvolvimento Agrícola, Projeto Dom Helder Câmara, 2001.

ALMEIDA, L. M. M. C.; FERRANTE, V. L. S. B. Programas de segurança alimentar e agricultores familiares: a formação de rede de forte 
coesão social a partir do Programa de Aquisição de Alimentos - PAA, no município de Araraquara, SP. In: CONGRESSO DA SOCIEDADE BRASILEIRA DE ECONOMIA, ADMINISTRAÇÃO E SOCIOLOGIA RURAL - SOBER. Anais... Porto Alegre, 2009.

ASSIS, L.; ROMEIRO, A. R. Agroecologia e agricultura orgânica: controvérsias e tendências. Desenvolvimento e Meio Ambiente, Curitiba, PR, n. 6, p. 67-80, jul./dez. 2002.

ÁVILA, V. F. Realimentando discussão sobre teoria de Desenvolvimento Local (DL). Interações, Campo Grande, MS, v. 8, n. 13, p. 133-140, set. 2006.

AZCÁRATE, T. G. Presente y futuro de la reforma de la PAC: una visión desde Bruselas. Agricultura Familiar en España, 2007. Disponível em: <http://www.upa.es/anuario_2007/pag_060-071_azcarate.pdf>. Acesso em: 8 jun. 2015.

BERGAMASCO, S. M. P. P. A realidade dos assentamentos rurais por detrás dos números. Estudos Avançados, São Paulo, v. 11, n. 31, p. 37-49, 1997.

BIANCHINI, V.; MEDAETS, J. P. P. Da revolução verde à agroecologia: plano Brasil agroecológico. 2013. Disponível em: <http://www.mda. gov.br/portalmda/sites/default/files/user_arquivos_195/Brasil\%20 Agroecol\%C3\%B3gico\%2027-11-13\%20Artigo\%20Bianchini\%20 e\%20Jean\%20Pierre.pdf>. Acesso em: 24 jun. 2015.

BONFIM, R. M.; BATALHA, M. O. A importância da confiança na relação entre produtores familiares de mamona e usinas de biodiesel no Brasil. In: ENCONTRO NACIONAL DE ENGENHARIA DE PRODUÇÃO, 32., Bento Gonçalves, RS, Brasil, 15 a 18 de outubro de 2012. Disponível em: <http:// www.abepro.org.br/biblioteca/enegep2012_TN_STO_157_915_20173. pdf>. Acesso em: 1a abr. 2016.

BORGES, J. L. Movimentos sociais e sustentabilidade: os desafios da "Extensão Rural Agroecológica" em assentamentos de Reforma Agrária. Revista Cesumar, Maringá, PR, v. 17, n. 1, jan./jun. 2012.

BRASIL. Ministério da Agricultura, Pecuária e Abastecimento. Evolução do cooperativismo no Brasil: DENACOOP em ação. Brasília: MAPA, 2006. $124 \mathrm{p}$.

BRUM, A. J. Modernização da agricultura: trigo e soja. Ijuí, RS: FIDENE, 1988. 
BUAINAIN, A. M.; GARCIA, J. R. Os pequenos produtores rurais mais pobres ainda tem alguma chance como agricultores? NAVARRO, Zander; CAMPOS, Sílvia Kanadani (Org.). A "pequena produção rural” no Brasil. Ganhar tempo é possível? Brasília: CGEE, 2013. 264 p.

CAPORAL, F. R.; COSTABEBER, J. A. Análise multidimensional da sustentabilidade: uma proposta metodológica a partir da agroecologia. Revista Agroecologia e Desenvolvimento Rural Sustentável, Porto Alegre, RS, v. 3, n. 3, jul./set. 2002.

COELHO, C. N. 70 anos de política agrícola no Brasil (1931-2001). Revista de Política Agrícola, Brasília, ano X, n. 03, jul./set. 2001.

CONFERÊNCIA DAS NAÇÕES UNIDAS SOBRE MEIO AMBIENTE E DESENVOLVIMENTO (CNUMAD). Agenda 21. 3. ed. Brasília: Senado Federal, 2000.

CONFERÊNCIA DAS NAÇÕES UNIDAS SOBRE DESENVOLVIMENTO SUSTENTÁVEL (CNUDS) - RIO+20. O futuro que nós queremos. 2012. Disponível em: <http://www.onu.org.br/rio20/documentos/>. Acesso em: 9 jul. 2015.

DE SOUZA BARBOSA, M. J. Desenvolvimento rural e economía solidária: estratégia de sustentabilidade sob procesos de intercooperaçao Espanha e Brasil na microrregiao do Baixo Tocantins - na Amazônia brasileira. In: GÓMEZ LÓPEZ, J. D.; DE SOUZA BARBOSA, M. J. (bajo la dirección de). Estrategias y acciones de desarrollo rural a través de Cooperativas y Emprendimientos Solidarios. Alicante, Espanha: AECIDOfibook, 2012.

ESPAÑA. Ministerio de Agricultura, Alimentación y Medio Ambiente. Caracterización del sector de la producción ecológica española: valor, volumen y mercado y evaluación del impacto del comercio electrónico en la producción ecológica española, 2013a. Disponível em: <http:// www.magrama.gob.es/imagenes/es/Informe\%20P\%20y\%20M\%20 Ecologico\%20-\%202012-WEB\%201-_tcm7-310968.pdf>. Acesso em: 24 jun. 2015.

ESPAÑA. Ministério de Agricultura, Alimentación y Medio Ambiente. Estrategia nacional de los programas operativos sostenibles a desarrollar por las organizaciones de productores de frutas y hortalizas. 2013b. Disponível em: <http://www.magrama.gob.es/es/agricultura/temas/ 
producciones-agricolas/ESTRATEGIA_NACIONAL_a\%C3\%B1o_2014_ tcm7-309360.pdf>. Acesso em: 1o abr. 2016.

ESPAÑA. Ministério de Agricultura, Alimentación y Medio Ambiente. La agricultura ecológica en España. 2015. Disponível em: <http://www. magrama.gob.es/es/alimentacion/temas/la-agricultura-ecologica/>. Acesso em: 22 jun. 2015.

EUR-LEX. Sintese de la legislacion de la EU. Reforma de la política agrícola común (PAC). [s.d.]. Disponível em: <http://europa.eu/legislation_ summaries/agriculture/general_framework/160002_es.htm>. Acesso em: 8 jun. 2015.

EUROPEAN COMMISSION. Overviw of CAP Reform 2014-2020. Agricultural Policy Perspectives Brief, n. 5, Dec. 2013. Disponível em: <http://ec.europa.eu/agriculture/policy-perspectives/policybriefs/05_en.pdf>. Acesso em: 25 jul. 2015.

FURTADO, C. Teoria e política do desenvolvimento econômico. São Paulo: Abril Cultural, 1983.

GIRARDI, E. P. Proposição teórico-metodológica de uma Cartografia Geográfica Crítica e sua aplicação no desenvolvimento do Atlas da Questão Agrária Brasileira. 2008. Tese (Doutorado em Geografia) - Faculdade de Ciências e Tecnologia, Universidade Estadual Paulista, Presidente Prudente, 2008. Disponível em: <www.fct.unesp.br/nera/atlas>. Acesso em: 3 fev. 2014.

GLIESSMAN, S. R. et al. Agroecología: promoviendo una transición hacia la sostenibilidad. Ecosistemas, v. 16, n. 1, Enero 2007. Disponível em: <http://www.revistaecosistemas.net/articulo.asp?Id=459\&Id_ Categoria=1\&tipo=portada $\geq$. Acesso em: 25 mar. 2016.

GÓMEZ LÓPEZ, J. D. Las cooperativas agrarias. Instrumento de desarrollo rural. Alicante, Espanha: Publicaciones Universidad de Alicante, 2004.

. El movimiento cooperativo agrario en España y la Unión Europea: evolución y cambios verificados ante el proceso de internacionalización del capital. Boletim de Geografia, Maringá, PR, v. 26/27, n. 1, p. 15-23, 2008/2009.

GUTIÉRREZ, F. R. El enfoque de las capacidades para la gobernabilidad del territorio. Ería, n. 63, p. 107-115, 2004. 
HISPA COOPE. Cuadernos de las cooperativas de consumidores. Confederação Española de Cooperativas de Consumidores y Usuarios. año XIII, n. 22, Octubre 2011. Disponível em: <http://www.hispacoop. com/home/index.php/2012-11-08-03-42-54/44-cuadernos-de-lascooperativas-de-consumidores-n-22/file>. Acesso em: 25 jun. 2015.

INSTITUTO DE PESQUISA ECONÔMICA APLICADA (IPEA). Financiando o desenvolvimento sustentável: o papel das compras públicas. In: Brasil em desenvolvimento 2011: Estado, planejamento e políticas públicas. Brasília: Ipea, 2012. v. 2.

JARA, C. J. A sustentabilidade do desenvolvimento local: desafios de um processo em construção. Brasília: Instituto Interamericano de Cooperação para a Agricultura - IICA; Recife: Secretaria de Planejamento do Estado do Pernambuco - SEPLAN, 1998. 316 p.

LA AGENDA 2000. Una política agrícola común para el futuro. 1997. Disponível em: <http://ec.europa.eu/agriculture/publi/ review99/08_09_es.pdf>. Acesso em: 25 jul. 2015.

LA DECLARACIÓN CORK. Hacia una política integrada de desarrollo rural. 1996. Disponível em: <http://www.femp.es/files/566-138archivo/Declaraci\%C3\%B3n_de_Cork_1996.pdf>. Acesso em: 25 jul. 2015.

LAGARDE, Olivier de. Quelle politique agricole pour l'Europe? In: Problèmes économiques. Paris: La documentation française, n. 2841, mercredi 28 janvier 2004. p. 6-12.

LEVI, M.; LINTON, A. Fair trade: a cup at a time? Politics \& Society, v. 31, n. 3 , set. 2003.

LOPES, F. D.; BALDI, M. Laços sociais e formação de Arranjos Organizacionais Cooperativos - proposição de um modelo de análise. $R A C$, Curitiba, PR, v. 9, n. 2, p. 81-101, abr./jun. 2005.

MARQUES, H. R. et al. Metodologia da pesquisa e do trabalho científico. 3. ed. Campo Grande, MS: UCDB, 2008.

MARTÍN, J. C. Los retos por una sociedad a escala humana: el desarrollo local. In: SOUZA, M. A. Metrópole e globalização: conhecendo a cidade de São Paulo. São Paulo: CEDESP, 1999. 
MARTINS, S. R. O. Desenvolvimento Local: questões conceituais e metodológicas. Interações - Revista Internacional de Desenvolvimento Local, Campo Grande, MS, v. 3, n. 5, p. 51-59, set. 2002.

MEDINA-ALBALADEJO, F. J. Fuentes para la historia de las cooperativas agrarias en españa: los archivos empresariales. Revista de Economia Publica Social y cooperativa, España, n. 77, p. 189-212, abr. 2013.

MOYANO-ESTRADA, E. Desarrollo local y cohesión em el marco de lanueva programación estratégica de la UE (2014-2020). Notas de palestra proferida no seminário "La estratégia Leader enel nuevo enfoque participativo de La Unión Europea para el desarrollo local (2014-2020)”. Salamanca, Espanha, 2013.

MOYANO-ESTRADA, E.; ORTEGA, A. C. A Reforma da PAC para o período 2014-2020: uma aposta no desenvolvimento territorial. RESR, Piracicaba, SP, v. 52, n. 4, p. 687-704, out./dez. 2014.

NASCIMENTO, C. A. A política agrícola comum da CEE e a ocupação das famílias rurais em atividades agrícolas e não-agrícolas: lições para a política agrícola no Brasil. Economia e Sociedade, Campinas, SP, v. 14, n. 2, p. 263-285, jul./dez. 2005.

NAVARRO, Z.; CAMPOS, S. K. A "pequena produção rural” no Brasil. Ganhar tempo é possível? Brasília: CGEE, 2013. 264 p.

OLIVEIRA, M. A. C. et al. Experiências agroecológicas brasileiras: uma análise à luz do desenvolvimento local. Revista Brasileira de Agroecologia, Pelotas, RS, v. 8, n. 2, p. 14-27, 2013.

ORGANIZAÇÃO PARA A COOPERAÇÃO E DESENVOLVIMENTO ECONÔMICO (OCDE). Agri-environmental policy measures: overview of developments. Paris: OCDE, 2003.

ORTIZ-PÉREZ, S. Um espacio cooperativo: soberania alimentaria y solidaridad internacionalista campesina. Barcelona: Icaria, 2015. $166 \mathrm{p}$.

PAULI, J. O poder nas redes de economia solidária. 2006. 180 f. Dissertação (Mestrado em Sociologia) - Universidade Federal do Rio Grande do Sul, Porto Alegre, RS, 2006. 
PIRES, Elson L. S. As lógicas territoriais do desenvolvimento: diversidades e regulação. Interações, Campo Grande, MS, v. 8, n. 2, p. 155-163, set. 2007.

REIS, C. F. B. Os efeitos do investimento público sobre o desenvolvimento econômico: análise aplicada para a economia brasileira entre 1950 e 2006. Brasília: ESAF, 2008.

SAMBUICHI, R. H. R. et al. (Org.). Políticas agroambientais $e$ sustentabilidade: Desafios, oportunidade e lições aprendidas. Brasília: IPEA, 2014.

SCHIMITZ, H. et al. Ação coletiva com fins econômicos: reflexões teóricas a partir de dois estudos de caso no espaço rural. 2007. Disponível em: <http://ainfo.cnptia.embrapa.br/digital/bitstream/item/60415/1/74. pdf>. Acesso em: dez. 2013.

SEVERINO, L. S. Desenvolvimento da agricultura orgânica no Nordeste. Fortaleza, CE: Banco do Nordeste, 2000. Disponível em: <http:// www.bnb.gov.br/content/Aplicacao/ETENE/Rede_Irrigacao/Docs/ Desenvolvimento\%20da\%20Agricultura\%200rganica\%20no\%20 Nordeste.PDF>. Acesso em: 17 nov. 2014.

SILVA, E. M.; CEREDA, M. P. Segurança alimentar, saúde, educação e lazer como fatores de base para desenvolvimento rural de um assentamento do Mato Grosso. Interações, Campo Grande, MS, v. 15, n. 2, p. 275-284, jul./dez. 2014.

SILVA, L. M. R.; KHAN, A. S. Educação, produção e eficiência na utilização dos fatores de produção na região semiárida do Nordeste. In: CONGRESSO BRASILEIRO DE ECONOMIA E SOCIOLOGIA RURAL, Aracaju, SE. Anais... Brasília: SOBER, 1996.

SOUSA FILHO, H. M.; BONFIM, R. M. Oportunidades e desafios para a inserção de pequenos produtores em mercados modernos. In: A pequena produção rural e as tendências do desenvolvimento agrário brasileiro: ganhar tempo é possível? Brasília: CGEE, 2013.

SOUZA, J. G.; DIEGUES, V. C. Por uma desglobalização da produção alimentar: commodização da agricultura e diversidade produtiva - uma análise de Espanha. GEOgraphia, Niterói, RJ, v. 14, n. 28 p. 63-81, 2012. 
SUCUPIRA, G. I. C.; FREITAS, A. F. de. Cooperativismo de crédito solidário: um arranjo institucional em prol do desenvolvimento local. $R E D E$, Fortaleza, CE, v. 6, n. 1, p. 23-40, mar. 2011.

SUMPSI, J. M. et al. La política agroambiental de la UE: un análisis desde la perspectiva económica. Revista de Economía Agraria, n. 179, p. 227 265, jan./abr. 1997.

VEIGA, J. E. da et al. O Brasil rural precisa de uma estratégia de desenvolvimento. Texto para discussão n. 1. Brasília: MDA/NEAD, 2001. 